\title{
AFASIAS: SELECCIÓN, COMBINACIÓN, SIGNOS Y FONEMAS
}

Con el término afasia se hace referencia a un padecimiento de "adultos cuya comunicación a través de una lengua natural ha sido afectada como consecuencia de un daño cerebral (LENNEBERg 1967, p. 188). De este planteamiento surgen diversas preguntas dentro de las cuales se pueden considerar las siguientes: 1) ¿qué daños cerebrales ocasionan esa disfunción lingüística?; 2) ¿qué aspectos de la comunicación lingüística han sido afectados?; y 3 ) ¿̨cómo debe procederse para la rehabilitación lingüística del paciente? Para responderlas hacen falta, respectivamente, un neurólogo, un lingüista y un terapeuta del lenguaje. El trabajo de equipo es, pues, fundamental para el estudio y tratamiento de este tipo de padecimientos. Por ahora, y dentro del marco del trabajo en equipo ${ }^{1}$ trataré de responder, así sea en forma limitada, a la pregunta que corresponde al lingüista.

Una lengua natural se caracteriza por estar doblemente articulada (Martinet 1965, Mounin 1969). En ella se encuentran signos -unidades con forma acústica y significado mediante las cuales se producen enunciados- y fonemas - unidades acústicas sin significado que permiten organizar y diferenciar los signos. De acuerdo con sus combinaciones, signos y fonemas se organizan en diversas jerarquías. En el caso de los signos, se ha considerado como unidad mínima al morfema, que se divide en dos clases: lexemas y gramemas (Potrier 1967). Los signos se organizan en la comunicación lingüística en jerarquías del tipo morfema-palabra-frase-oración-texto. Los fonemas aislados, vocálicos y consonánticos, forman sílabas; las sílabas se organizan en palabras y las palabras en grupos fónicos.

1 He realizado las investigaciones sobre afasia junto con el Grupo Mexicano de Estudios solre Afasiología, que se fundó en 1969. En él colaboran, además, los siguientes especialistas de las ramas médica y pedagógica: Pedro Perruecos Táles, María Paz y Pedro Berruecos Villalobos, Juan Carrasco Zanini e Isabel Farba. He realizado todas las entrevistas con pacientes del Instituto Mexicano de la Audición y el Lenguaje, de la ciudad de México. 
Por otra parte, como dice Jakobson (1967, p. 75), "hablar supone seleccionar determinadas entidades lingüísticas y combinarlas en unidades de un nivel de complejidad más elevado". En el proceso de comunicación, el emisor, para codificar un mensaje, va de una selección a una combinación de unidades, mientras que el receptor recibe una combinación y la descodifica mediante una selección por la cual reconoce las unidades. Tenemos, pues, que en la comunicación lingüística tanto el emisor como el receptor utilizan la combinación y la selección de signos y fonemas. La codificación va de selección a combinación mientras que la descodificación sigue el camino inverso.

En el lenguaje de un afásico uno o varios de los aspectos anteriores están afectados. Este hecho es el que ha permitido a Jakobson (1964), de acuerdo con los síntomas propuestos por Luria y siguiendo la clasificación de éste, replantear las afasias en términos de la disfunción lingüística que se presenta en cada una de ellas.

Luria considera seis tipos de afasias con las cuales Jakobson establece tres dicotomías. En la primera de ellas incluye las afasias eferente y sensorial, que corresponden respectivamente a perturbaciones en la codificación y en la descodificación. En la afasia eferente está afectada la capacidad de organizar las unidades lingüísticas en secuencias o sintagmas. La disfunción se manifiesta tanto en los signos como en los fonemas. En cuanto a los primeros, el habla de este tipo de pacientes muestra una pérdida de gramemas -morfemas o palabras-, de modificadores - adverbios, adjetivos, complementosy de pronombres o palabras que se pueden considerar dentro de la categoría general de sustitutos. En los casos severos el habla de estos pacientes se reduce a lo que se ha descrito como "lenguaje telegráfico". En el plano fonémico, el afásico eferente se caracteriza porque tiene dificultades en la asimilación de fonemas y en la formación de sílabas y porque, en ocasiones, presenta dislocaciones del acento de intensidad. La afasia eferente, incluida dentro de las codificadoras, presenta, sin embargo, algunas disfunciones en el proceso descodificador, ya que los pacientes de este tipo tienen problemas en la comprensión de gramemas.

La afasia sensorial, opuesta a la anterior, se caracteriza por una inadecuada descodificación de lexemas y de fonemas en oposición privativa. Los afásicos con este tipo de padecimiento, por otra parte, manifiestan un buen número de síntomas en el proceso codificador. En el plano fonémico, por ejemplo, se observa lo que en el habla normal se han llamado neutralizaciones de fonemas (Alarcos 1965), con la diferencia de que en el habla patológica las neutralizaciones se producen en posición explosiva y no sólo implosiva. En cuanto al plano morfémico o de los signos, los pacientes utilizan con frecuen- 
cia archilexemas o sustitutos en lugar de las palabras específicas; no les es posible encontrar antónimos o sinónimos ni pueden metaforizar, y producen fenómenos de tipo metonímico cuando, por ejemplo, se les pide que nombren determinados objetos o dibujos.

Ambas afasias, la eferente y la sensorial, presentan un lenguaje desintegrado: la eferente, en la dimensión sintagmática (fonemas y gramemas), y la sensorial, en la dimensión paradigmática (fonemas y lexemas).

La segunda dicotomía de Jakobson -limitación vs. desintegración- incluye las afasias dinámica y semántica. Ambos padecimientos son de tipo atenuado en comparación con los dos primeros y, frente a ellos, en la segunda pareja se presenta un lenguaje limitador. En la afasia dinámica están afectadas las "unidades del habla que sobrepasan los límites de la oración" (JAKoBson 1964, p. 31), de tal manera que los pacientes de este tipo, por su incapacidad de utilizar nexos, no pueden monologar y, en cambio, apoyados en el interlocutor, tienen mayores recursos para el diálogo. La afasia semántica se caracteriza por presentar una descodificación inadecuada de la "estructura lógico-gramatical del lenguaje" (Luria 1964, p. 156), lo que impide que estos pacientes comprendan las relaciones preposicionales o de caso y las permutaciones de elementos que no implican cambio de función. El afásico semántico, dice Jakobson $(1964$, p. 32), "asigna a cada clase de palabras una sola función específica" de acuerdo con el lugar que ocupa en la oración, por lo que los cambios en el orden de las palabras pueden confundirlo.

La tercera y última dicotomía de Jakobson enfrenta las afasias aferente y acústico-amnésica. De nuevo, como en la segunda dicotomía, se trata de casos no severos: en ambas está afectado sólo el plano fonémico. En la afasia aferente se presenta una disfunción de los elementos concurrentes en el fonema o, en términos de Luria, de los articulemas. El afásico aferente, aunque tiene la capacidad muscular de articular todos los fonemas de la lengua, muestra en su habla una selección inadecuada de determinados rasgos articulatorios que hacen que produzca un fonema por otro; por ejemplo, uno sordo en lugar del sonoro correspondiente, o uno continuo en lugar del interrupto. Una grabación del habla de este tipo de pacientes permitiría recoger todos los fonemas de la lengua en cuestión con la diferencia de que, en ciertos casos, ocurrirán unos donde se esperan otros. Frente a la afasia aferente, en la acústico-amnésica hay una disfunción de la secuencia fonémica que se observa fundamentalmente en la descodificación de enunciados o serie de palabras que incluyen fonemas en oposición privativa. En este sentido, el afásico acústico-amnésico puede caracterizarse por presentar una inadecuada discriminación de articulenas, lo que lo lleva a confundir, por ejemplo, pares mínimos de palabras. 
I

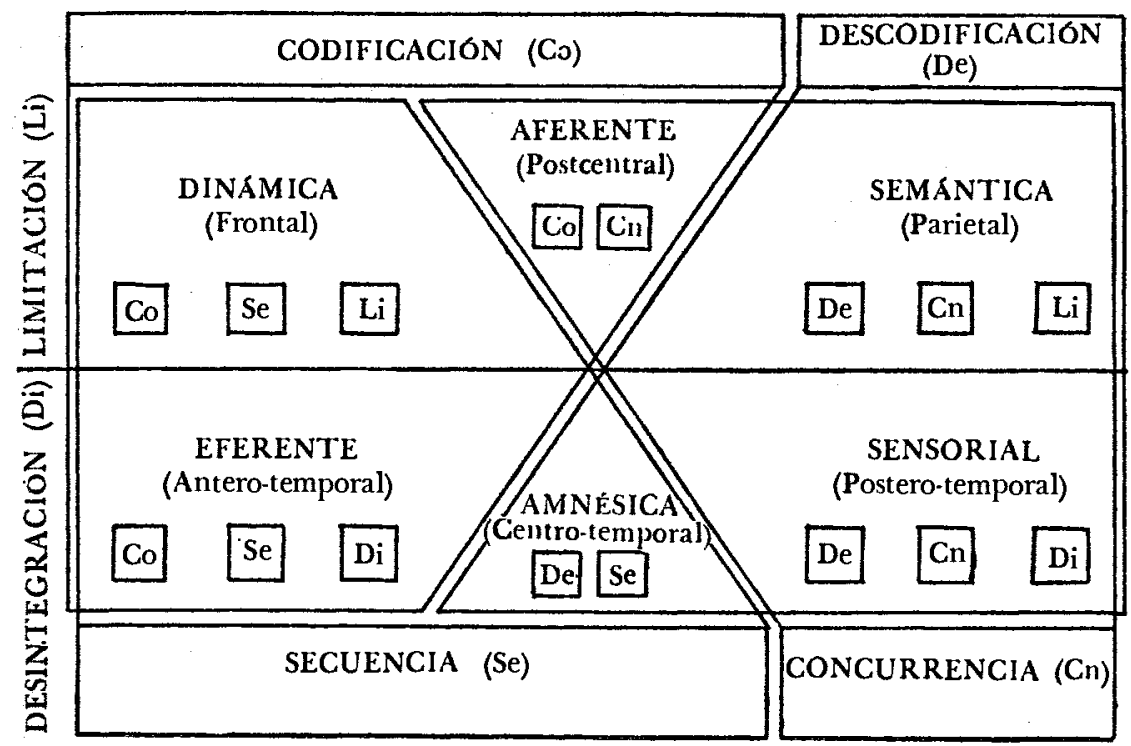

Las tres dicotomías anteriores y la clasificación de los seis tipos de afasias que surge de los planteamientos de Jakobson se muestran en el cuadro 1. En el mismo aparecen, de acuerdo con la terminología utilizada por Luria, las zonas cerebrales que resultan afectadas en cada uno de los padecimientos ${ }^{2}$.

Con la finalidad de confirmar los planteamientos de Luria y Jakobson con pacientes de lengua española, decidimos hacer un Cuestionario para el Estudio Lingüistico de las Afasias (CELA) mediante el cual se busca recoger los síntomas lingüísticos propuestos por esos autores ${ }^{3}$. Los aspectos principales del $C E L A$ son:

1) Diálogo, monólogo y descripción de láminas. Esta parte se registra magnetofónicamente, salvo en los casos de pacientes cuya codificación es nula o prácticamente nula. Mediante la grabación se estudia tanto el componente fonémico como el morfémico para ver qué elementos se conservan en una situación no condicionada por un interrogatorio rígido.

2 El cuadro ha sido tomado, con ligeras modificaciones, de Jakoвson 1964. Las zonas corresponden al hemisferio cerebral izquierdo, en el cual se localizan las funciones correspondientes a la comunicación lingüística en la mayoría de las personas, incluso las zurdas.

3 El $C E L A$, tras cuatro versiones experimentales que apliqué a más de cien pacientes, se publicó en su forma definitiva en 1976 . El cuestionario se aplica total o parcialmente a los pacientes, de acuerdo con el tipo de padecimiento que presenten y según los aspectos para los cuales es posible encontrar respues- 
2) Fonémica. Se estudian aquí los fonemas aislados y en combinaciones (palabras, series de palabras, oraciones y logotomos o secuencias fonémicas sin significado). Con excepción de las palabras, en todos los demás casos se incluyen fonemas en oposición privativa. En todos los ejercicios se pide al paciente que repita lo que escucha. En las series de palabras, además, el paciente debe señalar unos dibujos que corresponden a las palabras que escucha. Esto permite decidir, junto con el estudio del habla espontánea, si una pronunciación inadecuada se debe a un problema de descodificación o de codificación.

El apartado de fonémica permite recoger síntomas de cuatro tipos de afasias: eferente, sensorial, aferente y acústico-amnésica. Sin embargo, es insuficiente para delimitarlas, pues para cada una de ellas es necesario decidir si está o no afectado el componente morfémico.

3) Morfémica. Se incluyen tanto gramemas como lexemas. El estudio de los primeros permite evaluar cómo los utiliza el paciente, tanto en el nivel de morfemas como en el de palabras. Para ello se investigan sustitutos, artículos, nexos, concordancias y otros gramemas nominales y verbales. En cuanto a los lexemas, se observa cómo los selecciona el paciente mediante el procedimiento de denominar objetos o dibujos. Se obtienen más datos sobre el proceso de selección a través de la investigación del uso o supresión de elementos nucleares (sujetos, sustantivos y verbos). El uso inadecuado de gramemas y de combinaciones de signos caracteriza a la afasia eferente, mientras que una disfunción en la selección de lexemas es un síntoma de la afasia sensorial.

En la morfémica, además, se evalúa la descodificación de permutaciones sintácticas y de modismos (afasia semántica) y la capacidad metalingüistica del paciente en relación con el uso de sinónimos y antónimos (afasia sensorial).

4) Como aspectos complementarios se incluyen en el CELA la ejecución de órdenes, lectura, escritura y cálculo aritmético simple.

\section{CUATRo CASOS REPRESENTATIVOS}

Mediante la aplicación del cuestionario he podido encontrar cuatro de los seis tipos de afasias que describen Luria y Jakobson. Esos tipos están representados por los siguientes casos: 
I-I. B. L., hombre, 34 años, obrero.

Descodificación. Es adecuada en general, tanto de signos como de fonemas. Sólo tiene confusiones ocasionales en la comprensión de enunciados con permutaciones sintácticas y de órdenes complejas. Codificación. Puede pronunciar los fonemas aislados, pero le resulta difícil organizar sílabas y palabras. En cuanto a los signos, omite constantemente nexos (preposiciones y conjunciones) y elementos no nucleares (adverbios y adjetivos). La concordancia entre sustantivo y verbo es inadecuada porque suprime frecuentemente el gramema verbal de persona. Encuentra los lexemas en la denominación de objetos.

Muestra del habla espontánea. Ante la pregunta “¿Qué hizo usted hoy?", respondió: "pe persinár a la sí / a la sinko média // be besindá / pi pila labár rro rrópa súsia // guardár la kása / trabajár // a atóle / tamáles / trabajár / barrér / kabàr kubéta // trapeár / pe pershánas / sakudir pólbo mésa / arriba / abájo / eskaléra lòtra káie / eskaléra barrér / trapeár / lótra ///

Descodificación-codificación. Repite fonemas aislados, palabras y series de palabras, aunque tiene dificultades en la transición silábica.

Conclusión. Disfunción lingüística en la combinación de fonemas y signos que se observa sobre todo en la codificación.

II-G. O. de F., mujer, 42 años, ama de casa.

Descodificación. Tuvo confusiones frecuentes en la discriminación de fonemas en series de palabras. En el componente de signos tuvo errores sobre todo en adjetivos, tiempos verbales y adverbios; se confundió algunas veces con órdenes absurdas y muy frecuentemente con órdenes complejas.

Codificación. Los fonemas se conservan, salvo neutralizaciones ocasionales (/mañar/ por bañar, /kardín/ por jardin, etc.). Su codificación de signos le permite expresar enunciados extensos, aunque con evidentes dificultades. En ellos se aprecia una pérdida constante de sujetos y verbos. Los morfemas se mantienen en general, al igual que las demás clases de palabras, con excepción de las preposiciones.

Muestra del habla espontánea. El tema fue sugerido por la paciente. Se transcriben entre paréntesis los signos que, en opinión del investigador, fueron omitidos: "(fui al) teatro insurjéntes // (vi una obra) musikál / (trata de un) chikíyo // luego la kornéta tóka melódika / después / (la actriz) bàila múchas béses // (ella usa) mucha (ropa diferente) /// bestído // después (el chiquillo) bé a la eskuéla // después (ella recorre) el múndo / el múndo (con su) marído /// 
En la denominación de objetos se observan frecuentes metonimias (/sigárro/ por cenicero, /póyo/ por pato, /tenedór/ por cuchillo, /pála/ por martillo, etc.); algunas metátesis, omisiones de fonemas y omisiones de signos.

Descodificación-codificación. Repite normalmente los fonemas aislados y en palabras. Tiene confusiones muy frecuentes en las series de palabras y los logotomos, donde se aprecian metátesis y neutralizaciones de los rasgos sonoro/sordo y continuo/interrupto.

Conclusión. La disfunción lingüística abarca fonemas y signos y se manifiesta tanto en la codificación como en la descodificación. Lo más característico parece consistir en una perturbación del proceso de selección.

III-M. T. J. G., mujer, 42 años, obrera.

Descodificación. El componente de signos es aparentemente normal. Tiene confusiones frecuentes en el nivel de fonemas cuando se le presentan en series de palabras.

Codificación. Puede considerarse normal, tanto de signos como de fonemas, aunque hay algunos olvidos momentáneos.

Muestra de su habla espontánea: / ágo algúnos botónes de piél / i luégo / kuando ái kòsas de / kosér / por ejémplo / unos morráles / o bólsas / o sinturónes / yo los kóso // a béses ái unos lásos de piél // lásos de / de matrimónio / también yo lo / yo lo / yo los ágo // i a béses / kundo no téngo / kuando no téngo mùchas kósas ke asér / le ayúdo a la señóra asér la komída ///

Descodificación-codificación. Es normal la repetición de fonemas aislados y en palabras, pero los confunde frecuentemente en las series de palabras. Esta confusión de combinaciones fonémicas se observa también en el dictado. Escribió "la coma con borra" en vez de quita la coma con goma, "quera un gancho al callo" por quita un cacho al callo y "ven a la fuente por el puerte" en lugar de Ven por el puente a la fuente.

Conclusión. La disfunción lingüística parece localizarse únicamente en el plano fonémico, sobre todo en la descodificación de series de palabras con fonemas en oposición privativa. La codificación escrita (dictado) parece confirmar la inadecuada discriminación fonémica.

IV-G. T., hombre, 37 años, empleado.

Descodificación. Puede considerarse normal. Sólo tuvo confusiones ocasionales en el nivel fonémico durante la discriminación de series de palabras.

Codificación. Normal en el nivel de signos. En los fonemas se observan neutralizaciones frecuentes de los rasgos nasal/oral, so- 
noro/sordo (flojo-tenso) y continuo/interrupto. Hay además una nasalización frecuente de vocales.

Muestra de su habla espontánea: / estói trabajãndo / en na kononia / del páye [...] ase sínko meses ke sói en en trabájo / sínko o séis méses / en priméro te apríl / entré al trabájo // nó / de nopiembre [...] i: / asta óra nõ me án korrído / está múi bién / pero me / nopesiéntos pesos me / pakában / al més / pero ágo / ago: / múcho // a mi patrón le of ${ }^{(e)}$ résko / por ké no me súntupe / el suéldo / i bámos a $a^{b} e^{b}{ }^{(e)} /$ kon el injeniéro // akilár [...] la kõmpañía síke kresiéndo ///

Descodificación-codificación. Repite bien los fonemas aislados. En las palabras tiene confusiones semejantes a las que se observan


dáble/, etc. Se equivoca muy frecuentemente en la selección de fonemas cuando repite series de palabras. Transcribe adecuadamente al dictado, lo que parece indicar que la descodificación fonémica se mantiene mejor que la codificación.

Conclusión. Se observa una inadecuada selección fonémica en la codificación. Parece existir, aunque en menor grado, un daño similar en la descodificación.

Si se consideran los procesos de selección y combinación -que equivalen a paradigma y sintagma o, en términos de Jakobson, a concurrencia y secuencia- $y$, además, los componentes de signos y fonemas, podemos caracterizar los cuatro casos anteriores de la siguiente manera. En el primero está afectada la combinación de signos y fonemas; en el segundo, la selección de ambos componentes; en el tercero la combinación de fonemas; y en el cuarto la selección de los mismos.

Estos cuatro casos corresponden a los tipos que Luria y Jakobson ha descrito, respectivamente, como afasias eferente, sensorial, acústico-amnésica y aferente. Los otros dos tipos que incluyen estos autores y que no encontré en mis investigaciones son la afasia dinámica y la semántica. Es posible, sin embargo, de acuerdo con los datos bibliográficos, describir ambos tipos como disfunciones del componente de signos: la afasia dinámica en cuanto a la combinación y la semántica en cuanto a la selección.

"Hay evidencias en los afásicos -señala Taylor $(1969$, p. 1) que sugieren firmemente que la presencia de una disfunción en la comprensión siempre predice la presencia de una disfunción en la producción". Sobre esto, Jakobson (1964, p. 26) comenta que los términos disfunción codificadora y descodificadora "podrían ser usados con un añadido opcional: predominantemente codificadora y predominantemente descodificadora, ya que las anomalías en una 
de las dos funciones generalmente afectan también la función opuesta. Esto es particularmente cierto en la descodificación, cuyo mal funcionamiento afecta a la función codificadora mucho más que vice versa".

El hecho de que una perturbación en uno de los dos procesos afecta también al otro se confirma en los cuatro casos que he presentado, ya que en ellos se observa, en mayor o menor grado, la disfunción lingüística tanto en la codificación como en la descodificación. Ya antes había dicho (Ávila 1971, p. 62, nota) que Luria evita los términos codificación y descodificación por insuficientes. Agrego ahora que la afasia eferente o de Broca, considerada típicamente codificadora, corresponde según Pierre Marie (apud Lecours 1977 , p. 474) a "la concomitancia de una afasia de Wernicke (sensorial) y de una anartria", es decir, a un problema que afecta a ambos procesos.

En cuanto a los dos tipos de afasias que no he encontrado, la dinámica y la semántica, los datos bibliográficos permiten considerar que en ambas se presentan también problemas en la codificación y en la descodificación. De acuerdo con Lecours (1977, p. 259), en la afasia dinámica "la comprensión del lenguaje usual parece normal; sin embargo, las pruebas de comprensión relativamente complejas resultan en general mal resueltas". La afasia semántica, ubicada en las descodificadoras por Jakobson, presenta, además de este tipo de perturbación, otros en el proceso codificador, como la "incapacidad de ordenar unos componentes en relación con otros en un discurso elaborado" (Head, apud Lecours 1977, p. 484). El mismo Jakobson (1964, p. 33) cita para la afasia semántica un ejemplo de Wepman en la codificación: " $M i$ esposa no está aquí hoy. Él no vino conmigo" 4 .

Consecuentemente, aunque es de gran importancia observar si los daños se manifiestan en la codificación o en la descodificación, no parece conveniente utilizar estos dos procesos para la clasificación lingüística de las afasias ya que, si ambos están afectados en todos los tipos, no resultan pertinentes. Aunque mi experiencia es limitada, considero que sería suficiente operar sólo con los procesos de selección y combinación y con los componentes morfémico (signos) y fonémico (fonemas). De esta manera, las disfunciones de cada uno de los seis tipos de afasias a los que me he referido serían las que presento en el cuadro 2.

El Colegio de México.

RaÚl Ávila

$4 \mathrm{El}$ ejemplo está en inglés en el original: "My wife is not here today. He did not come with me". 


\section{II}

Tipos de afasias *

disfunción
proceso componente
combi- cobservable en
selección nación signos fonemas codif. descod.

1. combinatoria

(L: eferente)

2. selectiva

(L: sensorial)

3. acústica

(L: acústicoamnésica)

4. fonémica

(L: aferente)

5. dinámica

(L: dinámica)

6. semántica

(L: semántica)

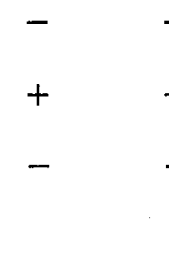

$\begin{array}{ccccc}+ & + & + & + & (+) \\ - & + & + & + & + \\ + & - & + & (+) & + \\ - & - & + & + & (+) \\ + & + & - & + & (+) \\ - & + & - & (+) & +\end{array}$

* " + " indica la presencia y " _" la ausencia de la disfunción. Se utiliza " $(+)$ " para señalar que el daño es observable en menor grado. Incluyo las denominaciones que se han usado en el Grupo Mexicano de Estudios sobre Afasiología, junto con sus equivalencias en términos de Luria.

\section{REFERENCIAS BIBLIOGRÁFICAS}

Alarcos 1965: Emilio Alarcos Llorach, Fonologia española, Madrid, 1965.

Ávila 1971: R. Ávila, "Sobre un cuestionario para el estudio linguístico de las afasias", Acta Audiológica y Foniátrica Hispanoamericana, México, t. 7, 1971, pp. 61-72.

CELA = R. Ávila et al., Cuestionario para el estudio lingüístico de las afasias, México, 1976.

JAKOBson 1964: R. Jakobson, "Towards a linguistic typology of aphasie impairments", en A. V. S. de Reuck y M. O'Connor (eds.), Disorders of language (London, 1964), pp. 20-45.

Jakobson 1967: Roman Jacobson y Morris Halle, Fundamentos del lenguaje, Madrid, 1967.

Lecours: André Rocn Lecours, et al., Traité d'aphasiologie, Paris, 1977. (En prensa).

LeNneberg 1967: Eric H. Lenneberg, Biological foundations of language, New York, 1967 .

Luria 1964: A. R. Luria, "Factors and forms of aphasia", en A. V. S. de Reuck y M. O'Connor (eds.), Disorders of language, London, 1964, pp. 143-161.

Martinet 1965: ANDRÉ Martinet, Elementos de lingüistica general, Madrid, 1965.

Mounin 1968: Ggorges Mounin, Claves para la lingüistica, Barcelona, 1968.

Pottier 1967: Bernard Pottier, Présentation de la linguistique, Paris, 1967.

TAYLOR 1969: O. L. TAYLOR, "Aphasia research at Indiana University", Lan. guage Sciences, Bloomington, 1969, mínı. 5. 